\title{
Disseminated Strongyloidiasis
}

\section{Flávio Mileo Bacelar Guerreiro, Celso Tavares Sodré, Lorena Brandão Pavan, Paulo Feijó Barroso, Daniele Carvalho Quintella, Tullia Cuzzi, Marcia Ramos-e-Silva}

\author{
University Hospital and School of Medicine - Federal University of Rio de Janeiro, Brasil
}

\author{
Corresponding author: \\ Professor Marcia Ramos-e-Silva, MD, PhD \\ Rua Dona Mariana 143 / C-32 \\ Rio de Janeiro 22280-020 \\ Brazil \\ ramos.e.silva@dermato.med.br
}

Received: April 13, 2018

Accepted: November 15, 2018

\begin{abstract}
Strongyloidiasis is a parasitic infestation caused by the helminth Strongyloides stercoralis. It is essentially gastrointestinal and in general asymptomatic but can sometimes present with skin signs. Immunocompromised patients can develop the disseminated form of the disease due to the parasite's opportunistic behavior, as in cases of coinfection by the human T-lymphotropic type 1 virus (HTLV-1). This article presents a case of a patient infected with HTLV-I and Strongyloides stercoralis who developed the disseminated form. There were purpuric reticulated periumbilical lesions as well as vibices on the patient's flanks. Histopathologic exam of a skin lesion revealed the presence of larvae in the deep reticular dermis. We emphasize the relevance of awareness regarding interaction between HTLV-1 and strongyloidiasis, besides identification of the cutaneous manifestations of the disease to reach an appropriate therapeutic diagnosis.
\end{abstract}

KEY WORDS: strongyloidiasis, Strongyloides stercoralis, HTLV-1

\section{INTRODUCTION}

Strongyloides stercoralis is a parasitic helminth worm that can be present in the soil and is capable of producing an infestation that may persist for decades. Its worldwide prevalence is estimated at around 100 million infected individuals, reaching up to $50 \%$ in Latin America and Africa, and may cause death (1).

The initial infestation cycle occurs as the filarial larvae penetrate the skin by direct invasion through the epidermis, reaching the subcutaneous tissue, penetrating into its vessels. They are then drained by the venous system until they reach the right heart chamber. Subsequently they arrive at the lung capillaries, traversing the alveolus from where they follow upwards through the bronchial tree and are finally swallowed in the gastrointestinal tract (2).

Infected patients may be asymptomatic or present diverse clinical manifestations that may resemble a simple peptic disease or present with a severe disseminated form of strongyloidiasis, if the larvae penetrate the intestinal mucosa, reaching the blood stream, causing bacteremia, meningitis, and sepsis, especially by Gram-negative bacteria (3).

Disseminated strongyloidiasis is defined by involvement of multiple organs besides the gastrointestinal tract and pulmonary system. It is especially common in immunosuppressed patients, and that is the reason human T-lymphotropic type 1 virus (HTLV1) represents a significant risk factor for development of hyperinfestation and more severe forms of this disease (4).

We describe a case of disseminated strongyloidiasis with cutaneous involvement in form of purpura that developed in an HTLV-1 infected patient.

\section{CASE REPORT}

A 53 year-old man working as a mechanic, born in the city of Recife, State of Pernambuco, Northeast of Brazil, arrived at the Emergency Room of the 
University Hospital with a 10-day history of migraine, diffuse abdominal pain, cough, fever, and constipation for 7 days. He had a history of colitis by Strongyloides treated in 2012.

At the time of admission, the patient reported having had an episode of hemoptysis the day before, with reduced consciousness level, respiratory failure, and cutaneous lesions in the abdomen. During physical examination, he presented tachypnea with 37 incursions per minute, respiratory difficulty, and $60 \%$ oxygen saturation, receiving a supplementation via oxygen mask at a rate of $5 \mathrm{~L} / \mathrm{min}$.

Reticulated periumbilical purpuric lesions were found at dermatological exam, along with small vibices in the flanks (Figure 1).

Due to the picture of respiratory failure, the patient was submitted to orotracheal intubation with a ventilatory prosthesis. Additionally, skull, abdomen, and pelvis CT scans were carried out, as well as general laboratory analyses. The tomography results indicated: normal skull, thorax with diffuse bilateral alveolar infiltrate compatible with alveolar hemorrhage, and a diffuse thickening of right colon and second portion of the duodenum in the abdomen. Laboratory analyses revealed mild anemia, absence of leukocytosis and $2 \%$ of eosinophils, discrete increase of urea, and transaminases.

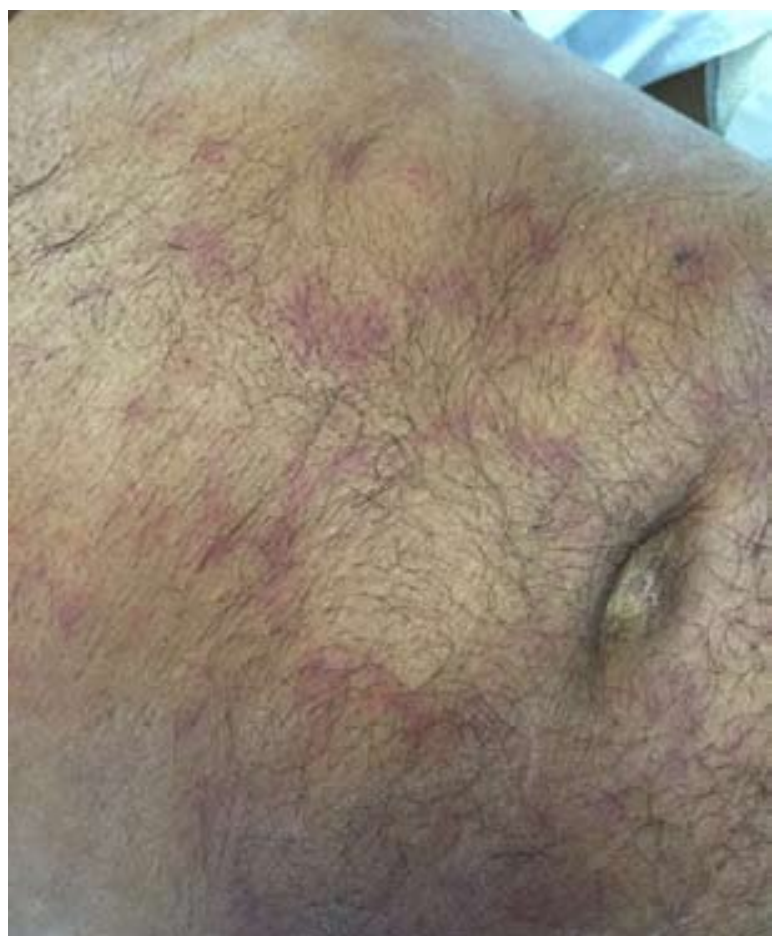

Figure 1. Reticulated and purpuric lesions on the periumbilical region.
The patient was sent to the Intensive Care Unit with treatment including daily administration of ivermectin @ $200 \mu \mathrm{g} / \mathrm{kg}$ via a nasoenteral probe because of the strong clinical suspicion of disseminated strongyloidiasis. Subsequently, bronchoscopy and bronchoalveolar lavage were carried out, as well as upper digestive endoscopy with biopsy of the second duodenal portion and scalpel biopsy of the cutaneous abdominal lesion. During bronchoscopy, a moderate amount of clots were found in the main right bronchus. Cytological analysis of the bronchoalveolar lavage revealed alveolar macrophages, ciliated cylindrical cells, neutrophils, and Strongyloides stercoralis larvae (Figure 2).

Histopathologic exam of the duodenum disclosed abundant larvae in the intestinal tissue (Figure 3) and, after cutaneous biopsy, the findings included a few inflammatory cells, extravasation of red blood cells, and presence of larvae throughout the reticular dermis (Figure 4), permitting the establishment of a final diagnosis of disseminated strongyloidiasis. During patient follow-up, HTLV-1 serology was positive for Elisa and Western-Blot.

\section{DISCUSSION}

Strongyloidiasis can be asymptomatic or present extensive symptomatology including a disseminated form (5). The symptoms presented by our patient, such as headache, abdominal pain, low consciousness levels, and dyspnea, belong to the picture of manifestations of the most severe form of the disease.

The most common cutaneous manifestations are purpuric, reticulated periumbilical lesions that may even affect the proximal region of the lower limbs. In our case, in addition to the typical lesions, small

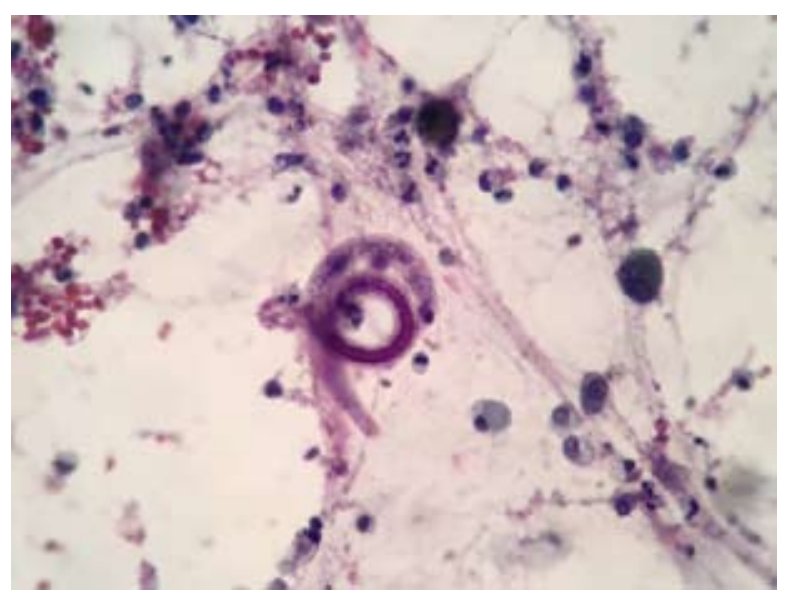

Figure 2. Cytological exam: alveolar macrophages, ciliated cylindrical cells, neutrophils, and Strongyloides stercoralis larvae (Papanicolau, $\times 400$ ). 


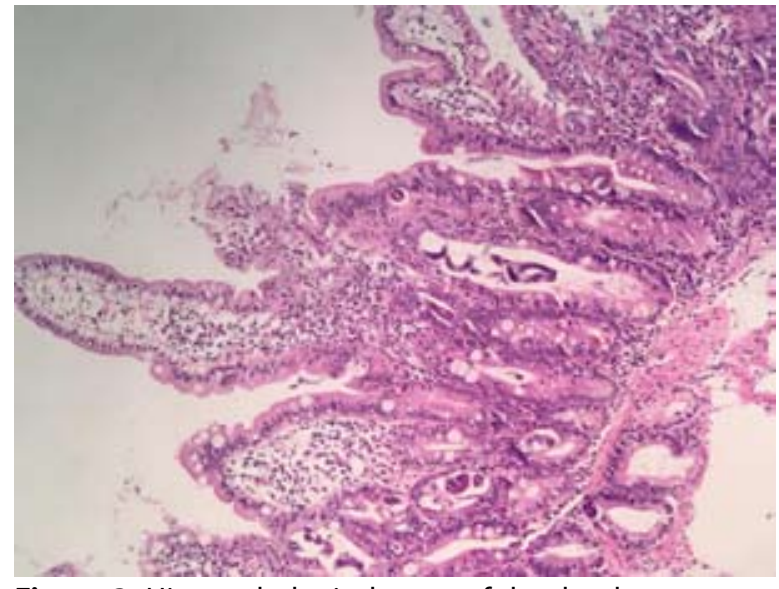

Figure 3. Histopathological exam of the duodenum: presence of larvae in the intestinal tissue (hematoxylin and eo$\sin , \times 100)$.

vibices were also found in the flanks, as already previously mentioned in the literature (6). The initial infestation cycle occurs when the filarial larvae penetrate the skin by direct invasion through the epidermis, trespassing all dermal levels till the subcutaneous tissue. They reach larger vessels that allow their migration to the lung capillaries. In that location they invade the alveoli, climb the bronchial tree and are then swallowed into the gastrointestinal tract where they reproduce, especially in the small intestine $(7,8)$.

The disseminated form of strongyloidiasis is considered an event with high mortality, due to the vast larvae reproduction in the digestive tube that migrate through the blood flow, thus causing systemic dissemination and being able to reach the skin, gastrointestinal tract, lungs, and brain. The symptoms are variable, including fever, rashes, vomiting, and respiratory discomfort (6). These semiological findings, even if unspecific, taken together with the epidemiologic history and previous pathologic history lead us to carry out an investigation of the cytological analysis of the bronchoalveolar lavage, biopsy of the duodenum, and cutaneous histopathology aiming to find larvae in the tissues in order to define the diagnosis.

The factors related to a greater probability for occurrence of disseminated strongyloidiasis are those that cause immunosuppression, especially in cases where high doses of corticosteroids have been used (even for short periods): presence of AIDS, lymphomas and leukemia, and especially infection by HTLV1. Several studies $(5,8,9)$ describe a significant association between HTLV-1 and hyperinfestation by S. stercoralis. There is also a reduced therapeutical response in patients infected with the virus concurrently with chronic strongyloidiasis. This may be caused by high levels of interferon gamma (IFN- $\gamma)$, which cause de-

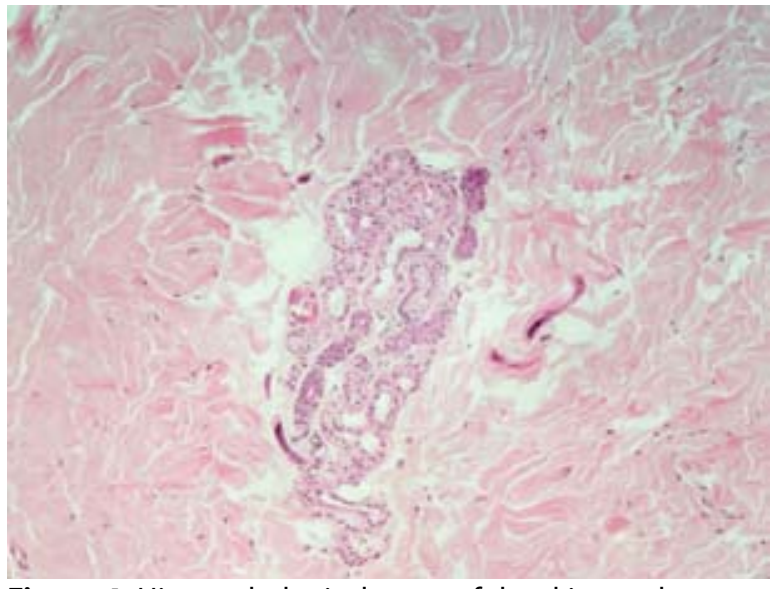

Figure 4. Histopathological exam of the skin: erythrocytes extravasation, few inflammatory cells, and presence of larvae in the reticular dermis around the sweat glands (hematoxylin and eosin, $\times 400$ ).

viation of the immune response for T-helper 1 (Th1) instead of T-helper 2 (Th2), responsible for protection against helminths (10).

In the disseminated form, an early diagnosis and immediate treatment are of extreme relevance for a better prognosis. The most frequent treatment options include thiabendazole, ivermectin, and albendazole. Ivermectin is a semi-synthetic anti-helminthic drug derived from avermectin B1, with a structure similar to macrolides but without antibacterial action, frequently prescribed for intestinal infestations by helminths. Ivermectin is better tolerated when compared with thiabendazole, having become the medication of choice for treatment of all forms of infestation. This medication operates through hyperpolarization of the neural cells, generating blockage of the motor nerve synapse with consequent death of the parasite caused by paralysis. The effect does not occur in humans, since the substance is unable to pass the hematoencephalic barrier. It is employed as treatment in several countries, as for instance United States and United Kingdom, based on several comparative trials that proved its efficacy $(11,12)$.

However, a major limitation is the bioavailability of the drug in cases of disseminated disease forms. Patients with disseminated forms often present lesions in the intestinal lymph vessels as well as in the intestinal mucosa caused by the parasite itself, resulting in edema of the intestinal wall, reduction of absorption, and paralysis of the ilium, resulting in poor absorption of the anti-helminthic drug. According to previously published reports $(13,14)$, veterinary preparation ivermectin can be administered by the parenteral route. 


\section{CONCLUSION}

We described an uncommon case of a patient with infestation by Strongyloides stercoralis associated with HTLV-1, as well as the cutaneous findings provoked by the helminths. This parasitic disease is potentially lethal and requires a high degree of clinical awareness in order to establish the correct diagnosis. In this case, the presence of the dermatologist was crucial to reach the correct diagnosis.

\section{References:}

1. Neumann I, Ritter R, Mounsey A. Strongyloides as a cause of fever of unknown origin. J Am Board Fam Med. 2012;25:390-3.

2. Luna OB, Grasselli R, Ananias M, Pinto TS, Bozza FA, Soares M, Salluh JI. Disseminated strongyloidiasis: diagnosis and treatment. Rev Bras Ter Int. 2007; 19:463-8.

3. Moura EB, Maia M de O, Ghazi M, Amorim FF, Pinhati HM. Salvage treatment of disseminated strongyloidiasis in an immunocompromised patient: therapy success with subcutaneous ivermectin. Braz J Inf Dis. 2012;16:479-81.

4. Mejia R, Nutman TB. Screening, prevention, and treatment for hyperinfection syndrome and disseminated infections caused by Strongyloides stercoralis. Curr Opin Infect Dis. 2012;25:458-63.

5. Naves MM, Costa-Cruz JM. High prevalence of Strongyloides stercoralis infection among the elderly in Brazil. Rev Inst Med Trop Sao Paulo. 2013;55:309-13.

6. Von Kuster LC, Genta RM. Cutaneous manifestations of strongyloidiasis. Arch Dermatol. 1988;124:1826-30.
7. Buonfrate $D$, Requena-Mendez $A$, Angheben $A$, Muñoz J, Gobbi F, Van Den Ende J, et al. Severe strongyloidiasis: a systematic review of case reports. BMC Infect Dis. 2013;13:78.

8. Greaves D, Coggle S, Pollard C, Aliyu SH, Moore EM. Strongyloides stercoralis infection. BMJ. 2013;347: f4610.

9. Furtado KC, Costa CA, Ferreira LSC, Martins LC, Linhares AC, Ishikawa EA, et al. Occurrence of strongyloidiasis among patients with HTLV-1/2 seen at the outpatient clinic of the Núcleo de Medicina Tropical, Belém, State of Pará, Brazil. Rev Soc Bras Med Trop. 2013;46:241-3.

10. Cabral AC, Iñiguez AM, Moreno T, Bóia MN, Carvalho-Costa FA. Clinical conditions associated with intestinal strongyloidiasis in Rio de Janeiro, Brazil. Rev Soc Bras Med Trop. 2015;48:321-5.

11. Segarra-Newnham, M. Manifestations, diagnosis, and treatment of Strongyloides stercoralis infection. Ann Pharmacother. 2007;41:1992-2001.

12. Keiser $\mathrm{PB}$, Nutman TB. Strongyloides stercoralis in the immunocompromised population. Clin Microbiol Rev. 2004;17:208-17.

13. Chiodini PL, Reid AJ, Wiselka MJ, Firmin R, Foweraker J. Parenteral ivermectin in Strongyloides hyperinfection. Lancet. 2000;355:43-4.

14. Salluh JIF, Feres GA, Velasco E, Holanda GS, Toscano $L$, Soares M. Successful use of parenteral ivermectin in an immunosuppressed patient with disseminated strongyloidiasis and septic shock. Intensive Care Med. 2005;31:1292. 